\title{
Finding the Best Instrument for a Case Study with the Help of Websites and Internet
}

\author{
Tang Tang \\ School of Foreign Languages and Cultures, Beijing Wuzi Univeristy, China \\ tangtang@bwu.edu.cn
}

\begin{abstract}
This paper aims to find the best instrument for a question: to what extent is teaching experience an advantage to Chinese teachers of English at Beijing Wuzi University. There are three aspects discussed and examined. Firstly, a case study could be an appropriate approach for this research. This is largely attributed to the nature of the study. Secondly, a triangulation method which involves questionnaire, interview and classroom observation could be applied in this project. Thirdly, with the great help of websites and Internet, acting as both "insider" and "outsider", the researcher could be in a good position to collect data. Therefore, as findings show, with the great help of websites and Internet, a case study with triangulation could be the best instrument to answer the question.

Index Terms - Case study, Teaching experience, Instrument, Website, Internet
\end{abstract}

\section{Introduction}

According to the Longman Dictionary of Contemporary English (2004: 655), "experience" means "knowledge or skill acquired over time". In most professions, it is assumed that more experience will contribute to better and more effective performance, and language teaching is no different. This theory has been accepted by the majority of people and many experts. And plenty of literature could give backing to this theory from many aspects of language teaching. For example, Richards (1998: 87) stated that "teachers with little or no classroom experience will have a limited store of schemata to draw on in planning and teaching lessons". However, not all people agree with this idea. They (e.g. Day 1990; Appel 1995) argue that experienced teachers do not necessarily have better performance in class than inexperienced teachers. For instance, in research about self-reflection, Day (1990: 226) found, "teachers started getting tired through the years", and some of their work began to "peter out".

Therefore, "To what extent is teaching experience an advantage for Chinese Teachers of English." is a worthwhile question to be investigated (the research area is set specifically in what is a familiar area for the author: the School of Foreign Languages and Cultures, Beijing Wuzi University.) Meanwhile, finding an appropriate instrument for a case study in Chinese English classroom in this specific area would be a key point to objectively answer the question above. Thus this project will aim to answer the following methodological question: what is an appropriate instrument for a case study in the defined context?

However, the way of seeking the appropriate instrument would be no longer a traditional way, such as through city library, books, and magazines on the shelves. Websites would play a very important role in this piece of research and it would prove the fact that it is also the most efficient way to deal with such case. Considering the rapid development of computer technology, as a language teacher, I would rather adapt to depend on the help of websites to find the best instrument in my research.

\section{Literature review}

\section{A. Rationale of "case" and methodology}

Before I go to a detailed review of example cases conducted by previous experts, I would like to define my "unit of analysis" (Palma 2002: 72) as a case, and regard my investigation in the specific area as a case study. Therefore, firstly, I will find backing to demonstrate why case study is "the most appropriate approach for the nature of the research" (Palma 2002: 70) I want to undertake.

As Palma (2002) states, in order to find out an appropriate approach, we first should be clear of "the nature of the study" (Palma 2002: 70). Thus, I would describe my study's nature in this way: it analyzes the influence of ESL teaching experience on teachers in the Foreign Language Department of Beijing Wuzi University and tries to find out, in general terms, to what extent teaching experience is an advantage to Chinese teachers of English in the context.

According to Palma (2002: 72), case study is "the indepth study of a human phenomenon, which is unique and related to a particular context". This definition is echoed by MacDonald and Walker. In "Case-study and the social philosophy of educational research" (MacDonald and Walker 1975, cited by Bassey 1999: 24), they point out "case study is the examination of an instance in action". The choice of the word 'instance' is significant in this definition, because it implies a goal of generalization". And Cohen and Manion (1989: 124-125), in their book Research Methods in Education, share the view that "the purpose of such observation is to probe deeply and to analyze intensively the multifarious phenomena that constitute the life circle of the unit with a view to establishing generalizations about the wider population to which that unit belongs". Meanwhile, Stake (Stake 1995: xi, cited by Palma 2002: 72) argues "case study is the study of the particularity and complexity of a single case, coming to understand its activity within important circumstances". In addition, "in 1986, the report by the Carnegie Task Force on Teaching as a Profession, A Nation Prepared: Teachers for the 21st Century, recommends "case studies illustrating a variety of teaching problems should be 
developed as a focus of instruction". (1986: 76, cited by Richards 1998: 79) And according to Richards (1998: 79), case studies in education can "reveal ways of thinking about a significant teaching incident" and can "help reveal how the teachers' beliefs, knowledge, personality, and pedagogical reasoning" could be reflected in a particular context. In short, case study is a research approach which could be applied in a certain and specific context and people could draw more generalized ideas or thoughts from it. Although I am not so sure I could generalize what I would get in my context to a broader context because of some practical or cultural reasons, applying these definitions to my own case, I still may conclude that a "case study" approach could be applied in my research according to the nature of my study.

In addition, I have learned that there are two types of case study according to Stake (1995), and they are also introduced by Palma (2002). According to Stake (1995: 3, cited by Palma 2002: 73), case study can be either an "intrinsic" case study or an "instrumental" case study. In the light of my purpose, I would like to define my case study as "instrumental" one, because it is appropriate "when we have a research issue or general concern and decide to develop insight into that by examining a particular case" (Palma 2002: 73).

In this case, as Palma (2002: 80) describes, "multiple sources of data and data collection methods were utilized in order to achieve validity of findings through triangulation". Simply speaking, according to Cohen and Manion (1989: 272), "triangulation is characterized by a multi-method approach to a problem in contrast to a single-method approach". It involves "interview", "observation", "questionnaire" etc. And the multi-method approach also has been introduced by other people, such as Barker et al. (1995). They argue that the sole use of questionnaire to obtain reliable data can have certain drawbacks. For a variety of reasons, for example, some replies in questionnaires may not be entirely candid, thereby providing information which may radically alter the true picture. In addition, as Munn and Drever (1990: 4-5) claim, "like all techniques, questionnaires have their limitations". The typical limitations are "the information collected tends to describe rather than explain why things are the way they are" and "the information could be superficial". In this case, "interview" is regarded as a method which "enables in-depth discussion of possible explanation derived from the other sources and so contributes to narrowing the focus of the study" (Palma 2002: 76) Besides, in Yin's (1989: 23, cited by Palma 2002: 76) definition of case study, he suggests applying "multiple sources of evidence" rather than "relying exclusively on one source of data" (Palma 2002: 76). Therefore, in this circumstance, using a multi-method approach or so-called triangulation could be a more appropriate and more objective way to collect valid and reliable data and enable the researcher to "cross-validate the data obtained from different sources" (Palma 2002: 76).

The following literature review will focus on the methodology applied in some literature which has a similar context to the research question I am going to investigate.
The most typical example which is related to the research question could be Senior's (2006) The Experience of Language Teaching. According to the reviewer Adoniou (2007: 181-182) in ELT Journal, "the book is an engaging narrative, albeit a complex one, about the experience of language teaching, using the voices and experiences of hundreds of language teachers in the UK and Australia". In order to get dependable and convincing evidence, in this book, Senior's original research analysis is based on "hundreds of detailed observations and interviews" (Adoniou 2007: 181).

In another example, Hawkey (2006: 242-252) applies the three methods in his article Teacher and learner perceptions of language learning activity in ELT Journal. Hawkey (2006: 242-252) describes his methodology in data collection in this way: it is always difficult to combine "quantitative data (for example, test scores and closed questionnaire items) with qualitative data (for example, open-ended questionnaire responses, interviews and focus groups, classroom observations)." But throughout the study, it proved beneficial and feasible to "cross-check (or triangulate) related data from different sources and of different kinds". Hawkey (2006: 242252) further reports, "a total of 228 student questionnaires were administered in short and straightforward questions". The interviews in focus groups (including students, teachers, heads of schools and parents) were "semi-structured but usually developed into free discussion (mostly video-recorded for later analysis)". He also uses "classroom observations" to record the "timings, episodes, activities, participation, and materials".

As Adoniou (2007: 181-182) concludes, Senior describes a clear and explicit picture of "good teachers' teaching stories" through extensive data collection and analysis. It also could be inferred that Hawkey got quite detailed information through compound research methodologies. However, we should notice the research above both involved a great number of respondents (e.g. Hawkey 2006 involves 228 students; Senior 2006 involves hundreds of detailed observations and interviews). In addition, in Hawkey's research, "data for the impact study were collected over the 2001-02 school year (Hawkey 2006: 242-252), not to mention, in Senior's (2006) book, "the material for the book comes from Senior's own research conducted over a twelveyear period (Adoniou 2007: 181-182)". Therefore, the chosen area (Foreign Language Department, Beijing Wuzi University) could be considered as relatively small scale as it only involves about 50 Chinese teachers of English, and the limited research time which is scheduled for three months (from June, 2012 to August,2012) could also be regarded as a relatively short period. In such a context, what methodology could be more appropriate? The following literature could give some indications.

Richards (1998: 103-121) conducted a piece of research named "what's the use of lesson plans". In this research, he uses questionnaires, recorded follow-up interviews and classroom observations to collect data. In order to find out how experienced teachers differ from inexperienced teachers in using lesson plans, "sixteen teachers were selected to 
constitute two groups at City University of Hong Kong - one group had a average of 9.6 years of ESL teaching and another group had an average of 1.6 years of ESL teaching (Richards 1998: 108)". Through the three methods which are mentioned above, Richards (1998: 108-109) describes, questionnaires could discover teachers' "teaching philosophy, approach to lesson plan, frequency of using lesson plan etc"; the recorded follow-up interviews gave more detailed and concrete information of teacher's use of lesson plan, such as the description of "reasons for the departure from plan"; and the classroom observations honestly reflect "what the teacher really did and the activities that were employed in their classes".

Also in Richards' (1998) book, research was undertaken by Benjamin Li at City University of Hong Kong investigating how novice and experienced ESL teachers planned a reading lesson. Ten novice teachers who had little ESL teaching experience constituted the novice group; ten teachers with an average of five years' ESL teaching experience constituted the experienced group. "Each group was given the same lesson planning task and was asked to spend about one hour planning" (Richards 1998: 87). In the process of their lesson planning, the researcher observed their behavior, such as, the time they used. After their lesson planning, they were interviewed individually to report what problems they had encountered in preparing the lessons and how these were resolved.

From the previous literature, in a case study, it could be inferred that the application of triangulation which involves at least two research forms is used widely in either large scale or small scale research. Therefore, I will utilize data source triangulation by collecting data from "questionnaire" to students, "interview" to teachers and "classroom observation". These three types of data could give me a chance to more objectively find out how teaching experience influence ESL teachers with my own interpretations as well as the teachers' own interpretations.

\section{B. Rationale of websites utilization}

Here is a question that is why websites would be used in this case? To answer the question, I have to mention a great author named Diana Eastment. She writes her paper (2007: 187-189) with a fancy term "Second Life", which is a 3-D virtual world where people can create a cartoon-like character ('avatar') and interact with objects and other users. According to her, with the help of websites, language schools, teachers and researchers are free to contact with their students or peers anywhere anytime. There is a beautiful picture in the mind of the author. She merrily describes (2007: 187): "Teachers and students can move around in classrooms and resource areas, listen to podcasts together, read online documents, and talk to each other via Skype or similar software. They move jerkily, for sure, but it is a compelling world and highly motivating for those taking part." This is an irresistible temptation for language teachers and researchers because they find in this way teaching or research are becoming "dynamic, interactive and highly involving applications" and students are no longer recipients but "active participants" (Eastment, 2007: 187) . Therefore, in order to keep up-to-date, however in the field of language teaching or research, websites and Internet can never be ignored and overlooked. It is also true in this case. And the benefits and advantages brought by these new technologies in this case would be furthermore discussed and in details in the next part (Findings).

Moreover, she recommends several useful and helpful websitess and networks for language teachers, learners and researchers. Some of them are communicative and social, like My space, Skype and Face book; some of them are more educational with more international relevance, like Shambles; some of them are focused on foreign language teaching and can provide a series documents in PDF format, like Language ICT (Information Communication Technology). Besides, she suggests some blogs and journals which are concentrated on language education and research. Eric Baber gets some short descriptions and thoughts on articles or websitess he has come across in the area of ICT and language education; Graham Stanley's BLOG-EFL, packed with 'observations and comments on the use of weblogs, emerging technologies \& elearning tools'. The content is "technical, and packed with jargon, but it is full of news and good links, and sparkles with enthusiasm" (Eastment, 2007: 188). And according to her (Eastment, 2007: 188), the best online journal for the new technology is Language Learning and Technology. This refereed journal is now over ten years old, and appears three times a year. It carries articles, short commentaries, and wideranging reviews of books and software. The monthly Internet TESL (Teaching English as a Second Language) Journal is less academic, and is aimed at the classroom teacher. The articles (which are by no means limited to technology) are the regularly updated links to ESL-related (English as a Second Language) websitess. Meanwhile, she points out it is also worth keeping an eye on the Journal's 'Recently Submitted Links' section. The BBC/British Council Teaching English site has a collection of technology-related articles in its 'Think' section. "The articles are concise and clear, and currently include podcasting, webquests, concordancers, and 'blogging for ELT (English Language Teaching)"' (Eastment, 2007: 188).

Apart from Diana Eastment, there is another man has to be mentioned, he is David Eastment, the author of the The Internet and ELT (1999. The British Council and Summertown Publishing). In his paper, he precisely gives some accurate websitess for readers, such as Clip-Art.com, which "gives access to a database of over a hundred sites for free pictures and animations" (Eastment, 2001: 214) for language lessons; ELT Newsletter.com, which "has a new ELT article each week with a bias on new technology" (Eastment, 2001: 215); and TESL-EJ is the Web's longest-established ELT 'e-journal', which covers all aspects of ELT.

In this case, Eastment (2007: 189) list a relatively exhaustive chart currently available for language teachers and researchers as a piece of advice. For example: 
Second Life - www.secondlife.com,

Education-www.theconsultantse.com/education/education.asp,

Languages ICT - www.languages-ict.org.uk/,

Language Learning and Technology - 1lt.msu.edu/,

Internet TESL Journal - iteslj.org,

Teaching English-

www.teachingenglish.org.uk/think/think.shtml

\section{Findings}

First of all, in this part, two important points could not be ignored: 1) a justification of the instruments above in my research context. 2) the role of websites and Internet played in the research

\section{A. The justification of the instruments in my research context}

I have acquired a general idea from the previous literature review and concluded that "triangulation" could be adopted in this case. However, considering the practical factors in the context, I find carrying out the research using an appropriate instrument is a problem to be considered.

First, in this context, I have to involve two groups of respondents: teachers and students. For students, their feedback should be considered, because it is students themselves who have the right to answer the hypothesis in the research "Maybe students prefer younger and inexperienced ESL teachers in the context". As I have reviewed above, a questionnaire could help the researcher find a general idea from a relatively larger number of people. Munn and Drever (1990: 2) point out, "you can collect information from a quite large of number of people in one fell swoop." In addition, "a questionnaire could enable the analysis of responses to be straightforward". Furthermore, questionnaires have advantages like "efficiently using time; anonymity (for the respondent); and the possibility of a high return rate". In this case, a questionnaire could be an appropriate instrument for students because, on one hand, they are outnumbered the teachers and, on the other hand, most of the questionnaires don't require the respondents' names and some of the close-ended questions only require ticking boxes, therefore, for the respondents, it is easier to accept answering some questions, maybe including some personal questions, without being recognized. Then the respondents may be more willing to feed back their answers. Thereby the possibility of return rate could be relatively higher. For teachers, according to Oishi (2003: 1), "an interview is a purposeful conversation between participants". I would choose interview with teachers. The reasons exist in three advantages of interview in this context:

1) Oishi (2003: 173) shows, "interviews are aimed at getting at implicit aspects of experience to make them explicit" and researchers, through using interviews could "gather opinions, facts and stories, and gain insight into the experiences of others from the "inside",.

2) Also according to Oishi (2003: 172), interviews tend to provide more information on "what" and "why" to researchers, thereby making clear the reasons and results of the diversity of phenomena.

3) Because interviews are the interactions between researchers and respondents, respondents could be "encouraged to speak freely about whatever comes to mind regarding the interview topics". (Oishi, 2003: 171) Therefore, in order to collect the in-depth data as well as some items could not be covered by the researcher in advance, adopting semi-structured interview with teachers could be appropriate. In addition, as the researchers did in the literature above, classroom observation could be a complement for the interview with teachers in order to achieve more objective and comprehensive data.

Second, considering feasibility, I should consider the order of application of these instruments in the research. I intend to interview teachers first, then observe the class and give students questionnaire last. The reasons of this order could be clarified into the following two points: showing the respect to the teachers before questioning their students; giving the teachers a general idea of the goal of the research in advance and acquiring their cooperation.

\section{B. The role of websites and Internet played in the research}

The role of websites and Internet played in the research is another important point which could not be ignored, because it would be the key element in the success of this case.

Firstly, most of the literature above is drawn from the websites mentioned before. As we have discussed, unlike traditional way, websites and Internet bring a great advantage for the research. I could gather enough information and materials through Internet without making efforts and time to go to library and bookstores. For instance, in the "Literature Review" part, there is an author named Palma (2002) who has been mentioned frequently, whose works is repeatedly quoted and echoed in the research. As a Chinese English teacher in Beijing, thanks to MSN, I was honored to know a professor, John Naysmith, at the University of Portsmouth, England. He recommended the works of Palma to help with my research. At that time, this piece of writing was a master thesis which was unpublished, which means I could never have the chance to read the paper without the help of Internet. Specifically speaking, it was "emails". And it is Internet that helps me overcome the remoteness of the distance and timing which are the usual obstacles for paper writing and research.

Secondly, according to Cohen and Manion (1989: 124), "the case study researcher typically observes the characteristics of an individual unit". In order to carry out interpretive research, the researcher often "feels a need to become some sort of participant, so he/she can approach the situation from an experiential point of view". (Palma 2002: 75) However, being a participant observer may lead to some dangers. "How to keep critical distance" could be a question for researchers to answer cautiously. Without critical distance, being a participant observer, researchers would find their judgment would be influenced gradually by the human style interaction between participant observer and their respondents. 
Thereby, they could not convince the readers that their research product is objective and reliable. Therefore, in this case, the researchers would be suggested to jump out the faceto-face situation with respondents and find a higher position to glance back what they observed. But how to be objective and reasonable without the personal involvement would be a question here. Websites and Internet can help us out in this case. For example, in my context of Beijing Wuzi University, there is a webpage in its official websites which is focused on showing the classroom techniques, skills and philosophy from different teachers at this university. And all of these are recorded into open videos without any modification online. Therefore, Internet, once more provides a great access for researchers to observe the classroom and teachers' behavior objectively, reasonably in a critical distance.

Thirdly, according to the review and discussion above, therefore, I will adopt the three research instruments to collect data. They are a "questionnaire" to 80 students, 6-8 "interviews" to teachers and 8-10 "classroom observations" at Beijing Wuzi University.

1) The interview with teachers is the main part of my research. I will choose 6-8 experienced and inexperienced ESL teachers who are my colleagues as my respondents. With a semi-structured interview, I have a plan to have conversations with them casually. But the problems are followed immediately. For instance, they might be too busy with their work and family to spare enough time to sit down quietly to answer the questions; they might feel nervous and embarrassed during a face-to-face interview; they might need some time to make reflection when confronted with some critical questions, etc.. In this case, Websites and Internet can help. I could apply for an account in MSN, Skype or some other online social networking sites. Then I could have a chance to communicate with them whenever they want, wherever they are, and however they like without face-to-face embarrassment and time or space limitation. Of course all these are available in the consideration that most of my colleagues are users in such networking sites. Besides, in the process of interview, as Oishi (2003: 171) suggests, I would "take notes and tape-record the interview for later transcription, so that no detail is lost". In the "networking sites" way, the interviewer could save a totally comprehensive record of interview considering the recording trait of such networking sites.

2) Classroom observation is another main part of my research. Acting as a member of the class, I will choose 8-10 classes as well as 8-10 ESL teachers to observe. It aims to objectively answer what teachers really do in their class delivery. For this point, people may ask "do you think a teacher will do exactly the same as what they usually do when they are being observed?" It is a good question! Therefore, as we have discussed above, teaching videos on webpage in the university's websites would be observed and judged carefully. And here is another point has to be mentioned that the classroom behavior could be examined more carefully and exhaustively considering such videos online could be replayed over and over.
3) The questionnaire to 80 students is a relatively simple and straightforward one. It aims to collect the general point of view of students about ESL teachers with different teaching experience. But how to gather and analyze the huge data could be a vey tough task. Again, websites and Internet can help. In this case, the questionnaire could be handed out through emails to students. And there will be an answer sheet in the format of Excel. After gathering the data, it could be much easier to analyze through copy, paste and Excel calculation. In addition, if time permits, I intend to interview a few of the student leaders to achieve more detailed information. The reason I chose such interviewees is that such a group always tends to tell truth and seldom be afraid of authorities. Like the interview with teachers, I would adapt to some other social networking sites which would be more preferred among young people, like Weibo, Weixin, Fetion, or QQ etc..

In this relatively familiar context for the writer, with the help of websites and Internet, the data collection from the teachers and students is feasible, convincible and relatively sufficient. As referring to the definition of "experience", I tend to regard "teaching years" as "experience in teaching". It is generally considered that the more teaching years a teacher has, the more experience he or she acquires. However, whether it is true in the specific context I chose needs to be demonstrated. Therefore, I intend to draw a teachers' "biography picture" in this context through my observation and description. First, I would group the 6-8 teachers. Each two of them shares a similar teaching age will be in a group (The first group may be defined as the group with 2 or below teaching years; the second with average 5 teaching years; the third with average 10 teaching years and the fourth, if there is one, with average 15 or above teaching years.). Second, I would plot theses groups on a continuum, like the following graph:

\section{0}

25 teaching years

My task is to describe the teachers I choose on this continuum and observe whether they are different and how they change as time goes by. In other words, I may find the teachers' professional development in my chosen context. Therefore, my observation in class and the brief feedback from students, I presume that the vivid "biography" continuum may answer the question "To what extent is teaching experience an advantage to Chinese teachers of English?"

\section{Conclusion}

The result of this project may be summarized by pointing out, firstly, that a case study could be an appropriate approach for this research. This is largely attributed to the nature of the study. And a triangulation method which involves questionnaire, interview and classroom observation could be applied in this project. With the evidence from previous literature, this relatively objective research could be utilized. Besides, with the great help of websites and Internet, acting as both "insider" and "outsider", the researcher could be in a 
good position to collect data. Therefore, as findings show, a case study with triangulation could be the best instrument to answer the question "to what extent is teaching experience an advantage to Chinese teachers of English at Beijing Wuzi University". And it cannot be successful and objective without the great help of websites and Internet.

\section{References}

[1] Adoniou, M., The Experience of Language Teaching. ELT Journal, vol.61, no. 2, pp.181-182, 2007.

[2] Appel, J., Diary of A Language Teacher, Heinemann, Oxford, 1995.

[3] Barker, A., Frier, D., Graves, P., \& Suleiman, Y., The Evolution of Language Learning Motivation, with Some International Comparisons, CILT, London, 1995.

[4] Bassey, M., Case Study Research in Educational Settings, Open University Press, Buckingham and Philadelphia, 1999.

[5] Carnegie Task Force on Teaching as a Profession., A Nation Prepared: Teachers for the $21^{\text {st }}$ Century. Carnegie Forum on Education and the Economy, Carnegie Corporation, New York, 1986.

[6] Cohen, L. \& Manion, L. Research Methods in Education, Routledge, London and New York, 1989.

[7] Day, C. The Development of Teachers' Personal Practical Knowledge through School-based Curriculum Development Projects, Day, C., Pope, M., \& Denicolo, P. (eds.), Insights into Teachers' Thinking and Practice (213-239), The Falmer Press, California, 1990.

[8] Eastement, D., Teachers. ELT Journal, vol.55, no. 2, pp.214-216, 2001.

[9] Eastement, D., How Do You Keep Up-to-date? ELT Journal, vol.61, no. 2, pp.187-189, 2007.
[10] Frazer, L., \& Lawley, M., Questionnaire Design and Administration: a practical guide. Wiley, Milton, 2000.

[11] Hawkey, R., Teacher and Learner Perceptions of Language Learning Activity, ELT Journal, vol. 60, no. 3, pp. 242-252, 2006.

[12] Longman Dictionary of Contemporary English. Foreign Language Teaching and Research Press \& Longman, Beijing, 2004.

[13] Macdonald, B., \& Walker, R. Case-study and the social philosophy of educational research. In D. Hamilton et al. (eds). Beyond the Numbers Game: a Reader in Educational Evaluation. Basingstoke, Macmillan, pp.181-189, 1977.

[14] Munn, P., \& Drever, E., Using Questionnaires in Small-Scale Research: a teacher's guide, The Scottish Council for Research in Education, Edinburgh, 1990.

[15] Oishi, S.M., How to Conduct In-Person Interviews for Surveys, Sage, London, 2003.

[16] Palma, A., Contexts of Change: Primary Foreign Language Teaching as an Educational Innovation in Late $20^{\text {th }}$ Century Portugal. Unpublished master thesis, University of Southampton, Southampton, 2002.

[17] Patrick, J. A., Glasgow Gang Observed, Eyre Methuen, London, 1973.

[18] Richards, J. C., Beyond Training: Perspectives on Language Teacher Education, Cambridge University Press, Cambridge, 1998.

[19] Senior, R. M. The Experience of Language Teaching, Cambridge University Press, Cambridge, 2006.

[20] Spradley, J. P., Participant Observation, Holt, Rinehart and Winston, New York, 1980.

[21] Stake, R. E., The Art of Case Research, Sage Publications, Thousand Oaks, 1995.

[22] Yin, R. K., Case Study Research: design and methods, Sage Publications, Newbury Park, 1989. 